\title{
Algorithm for selecting the structures of coastal protection construction to ensure environmentally safe condition of the coastal urbanized recreational areas
}

\author{
Natalya Vetrova ${ }^{1,2}$,Elmar Mennanov ${ }^{1,2}$, Tatyana Ivanenko $^{1,2}$, Anastasia Gaysarova ${ }^{1,2}$, and \\ Emran Mennanov ${ }^{1}$ \\ ${ }^{1}$ V.I. Vernadsky Crimean Federal University, 4, Acad. Vernadsky ave, Simferopol, 295007, Russia \\ ${ }^{2}$ Russian Academy of Architecture and Building Science Research Institute of Building Physics, \\ 127238, Moscow, Russia
}

\begin{abstract}
The existing concepts and modern methods of ensuring the ecological safety of the coastal zone of the sea were analyzed. The article considers modern theoretical developments and methods of choosing design solutions for special structures - various coastal protection structures (permeable, impermeable, made of various building materials, various shapes). This paper suggests a new algorithm for the choice of Bank protection structures intending to ensure environmentally friendly seaside state urban recreation area from the position of the preservation or restoration of the beach zone, which affects the environmental parameters of the site, which consists of a data collection phase of the study object, the selection of natural and technical factors that affect the ecological security of seaside urban recreational areas, the definition of specialization of the coastal zone in terms of recreation attractiveness of the coast, the evaluation phase of the current dynamics of ecological safety of the beach zone of the shore as an important element of seaside recreation of the urbanized area, which affects the level of environmental security in general, stage select bank protection structures and the definition of the projected factors of ecological safety of the beach zone. To check the application of the algorithm of selection structures bridges to ensure environmentally safe condition seaside urban recreational areas allows further justify the selection of the optimal environmental engineering solutions for the protection of the Western coast of Crimea.
\end{abstract}

\section{Introduction}

The relevance of research on theoretical and applied approaches to ensuring the environmentally safe condition of urbanized territories in the coastal zone is determined by the marked deterioration of the parameters of the living environment in recent years almost everywhere and in the coastal territories of recreational specialization, in particular [1].

\footnotetext{
* Corresponding author: xaoc.vetrova.03@mail.ru
} 
These ecological processes are associated with an increase in the density of development and an increase in loads from various objects being constructed (residential buildings, infrastructure facilities, transport complexes, etc.), a reduction in natural complexes (forest, park plantations, protected areas, etc.), which requires solving the problems of organizing an engineering and environmental survey of coastal urbanized territories in general and recreational areas in particular [2,3]. Besides, there are violations of the technical condition of objects on the coast, including the destruction of coastal protection structures, wear of water supply and sewerage networks, which affect environmental pollution [4]. Attention should be paid to the state of the beach zones that form the seaside landscape, its comfortable parameters, where recreational services for health improvement and leisure are provided. It should be noted that for a long period in the coastal zone, a system of coastal protection facilities was formed, the purpose of which, among other things, assumed the preservation of coastal massifs from the destruction of wave action, including the preservation of beaches. The existing destruction of the system of coastal protection facilities violates the safety of the environment as a whole and creates dangers for the organization of tourism on the coast [5].

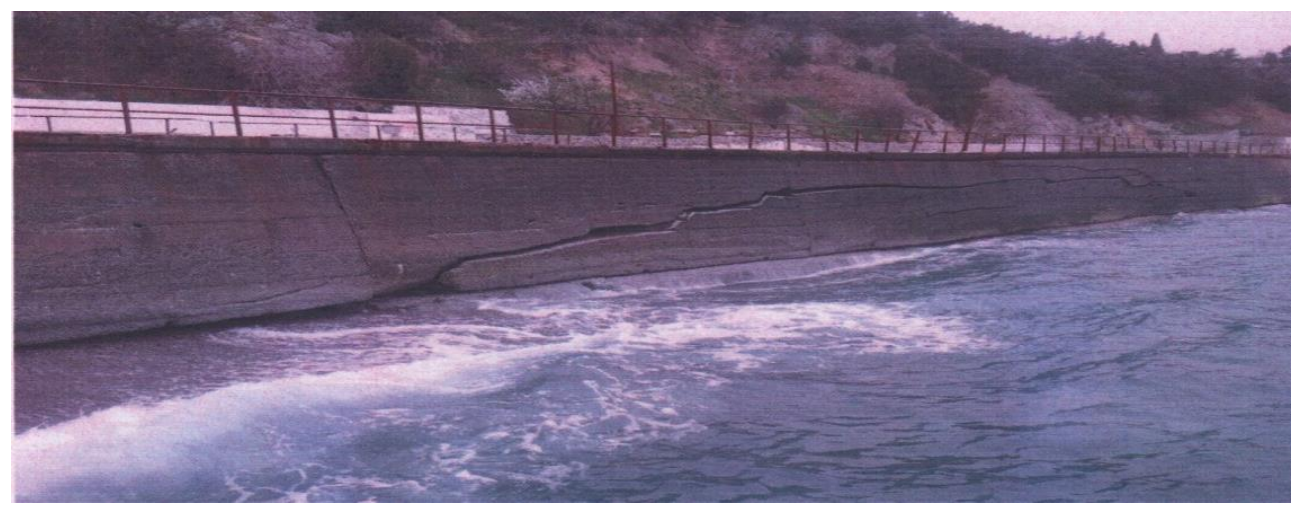

Fig. 1. Emergency condition of coastal protection structures in Yalta (Simeiz)

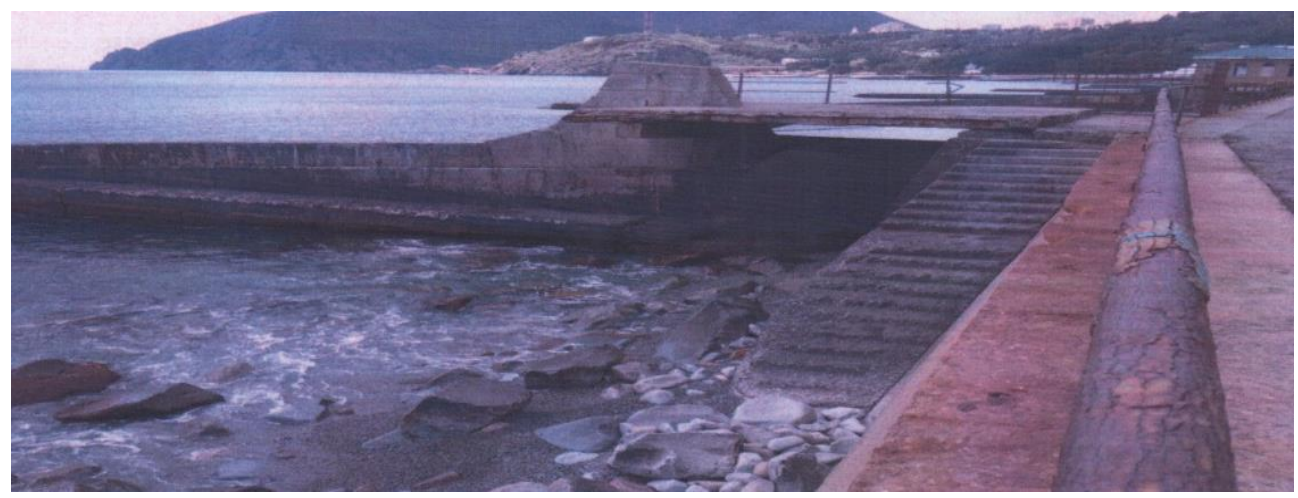

Fig. 2. Emergency condition of coastal protection structures in Yalta.

The purpose of the study is to substantiate the algorithm for choosing a variant of coastal protection structures, based on assessments of the ecological state of coastal territories and beach areas, significant patterns of processes in the banks that should be taken into account when designing coastal protection structures. To achieve this goal, a systematic analysis of 
the theoretical foundations of the choice of coastal protection structures was carried out, taking into account the experience of using bio-positive coastal protection structures and field surveys were conducted for 2015-2020. recreational zone of the western coast of the Crimean Peninsula, mathematical modelling was performed, which allowed us to determine the volume of losses of the embankment and beach territory, statistical generalizations of identifying trends in the state of the ecology of the coast. The choice of the coast of the Crimean Peninsula as the object of research is determined by the fact that the zone has a fairly complex geomorphological structure that is diverse, under special natural factors. An important anthropogenic factor is a recreational specialization of the territories that formed in the coastal area and has a significant impact on the transformation parameters of the coastal zones, coastal arrays, and underwater slopes beach [6]. Studies have identified the nature and extent of violations of the coastal zone of the sea and shore protection structures on the coast of the Kalamitsky Bay of the Black sea nears Sandy: as a result of significant destruction of reinforced concrete coastal protection structures, the loss of the coastal zone, violation of beach strips in terms of reducing the width and changing the quality of the beach material was revealed.

\section{Methods}

The development approaches of engineering and environmental design of Bank protection construction of seaside urban recreational areas is based on the theory of geomorphology, surface and underwater parts of the coast, the laws of hydrophysical parameters of the sea in the coastal zone, climatic and seismic conditions (Zenkovich, 1955), (Longinow, 1963), (Macheeva, 1968), (Esin, 1980), (Shooyski, 1986), (Romaniuk, 1997 [7]), and shall take into account the influence of natural and anthropogenic factors on the ecological parameters of the coastal zone (Goryachkin, 2015), (Vetrova, 2017), taking into account studies on numerical and experimental models on the example of the Crimean coast.

\section{Results and discussions}

When designing coastal protection structures, it is necessary to take into account that separate protection of small areas of eroded coastal territories within a large zone of the coast has low efficiency, because the adjacent unprotected banks will recede under the influence of a system of natural factors [8].

Synthesis of the results of theoretical and experimental studies of problems of ecological safety seaside urban recreational areas in the construction or reconstruction of shore protection structures on the example area of beach on the Western coast of Crimea allowed developing an algorithm for pre-project-selection, biopositive Bank protection structures at a reasonable informed method [9].

The algorithm of environmental security seaside urban recreational areas was based on the theoretical and methodological development V. A. Ivanov, A.V. Lushchik [7], S. P. Ivanyuta [10], V. T. Trofimov [11], Yu. N. Goryachkina [12], N. M. Vetrova, T. A. Ivanenko [13] and others, which beach zone stands out as a special system, which is open, and between it and the atmosphere, surface waters, bio- and technosphere is constant energy and mass transfer.

The algorithm for ensuring the environmental safety of coastal urbanized recreational areas involves the implementation of 5 stages, each of which solves local problems to achieve a common goal.

At the first stage, data on the object of research is collected and the natural man-made factors that affect the environmental safety of urbanized coastal recreational areas are identified. 
Since there are special rules for the construction of coastal protection structures for recreational areas [14], there is a need to understand whether the research area is recreational or not. For this purpose, at the second stage, the specialization of the coastal zone is determined by the level of recreational attractiveness of the coast based on previous studies [15]. As a result, the indicator of recreational attractiveness of the coastal zone $\mathrm{I}_{\mathrm{ra}}$ is determined:

if $\mathrm{I}_{\mathrm{ra}}<30 \%$ - the conditions for effective recreation are unfavourable and the conduct of recreational activities is not recommended;

if $\mathrm{I}_{\mathrm{ra}}=30-60 \%$ - the conditions for effective recreation are favourable, but the ecological condition of the territory is quite severely disturbed, which requires immediate action in the development of measures to improve the environmental safety of these territories;

if $\mathrm{I}_{\mathrm{ra}}=61-80 \%$ - the conditions for effective recreation are favourable, but the territory has violations of the ecological state, which requires the development of measures to improve the environmental safety of these territories, respectively;

if $\mathrm{I}_{\mathrm{ra}}=81-100 \%$ - the conditions for effective recreation are favourable and violations of the ecological state are either insignificant or absent.

At the third stage, the assessment of the current dynamics of the ecological safety of the beach zone of the coast is carried out as an important element of the seaside recreational urbanized territory, which affects the level of environmental safety in general. This assessment takes into account the influence of both natural and man-made factors.

In the methodology, the level of environmental safety of the beach zone of the $\mathrm{ES}_{\mathrm{ba}}$ shore is estimated by two parameters: $\mathrm{Ne}_{1}$-the degree of stability of the beach, $\mathrm{Ne}_{2}$-the degree of comfort of operation of the beach zone and is calculated by the formula:

Where:

$$
E S_{\mathrm{b} a}=\frac{N \mathrm{e}_{1}+N e_{2}}{2}
$$

$$
\begin{aligned}
& N e_{1}=\frac{\Sigma \Delta k_{1 k}^{e}}{n_{1} * m_{1}} * 100 \\
& N e_{2}=\frac{\Sigma \Delta k_{2 k}^{e}}{n_{2} * m_{2}} * 100
\end{aligned}
$$

where $n_{1}$ and $n_{2}$ are the numbers of indicators of each of the parameters, respectively; $\mathrm{m}_{1}$ and $\mathrm{m}_{2}$ are the maximum numbers of points for the first and second parameters, respectively.

The criterion is the indicator of the ecological safety of the beach area-ESba:

- if the $\mathrm{ES}_{\mathrm{ba}}$ increases and the $\mathrm{ES}_{\mathrm{ba}}$ is $>50 \%$, then we can say that the environmental safety of the beach zone is ensured;

- if the $\mathrm{ES}_{\mathrm{ba}}$ is less than $50 \%$ - the ecological safety of the beach zone is not ensured.

If an unsatisfactory level of environmental safety of the beach zone is noted with the existing systems of coastal protection structures, it is necessary to analyze the parameters of the technical condition and design solutions of these structures.

If the unsatisfactory level of environmental safety of the beach zone was affected by the lack of complexes of coastal protection structures, it is necessary to analyze possible design solutions of coastal protection structures that meet environmental criteria.

At the fourth stage, the selection of coastal protection structures is carried out following the regulatory document - SP 277.1325800.2016 "Coastal protection structures. Design rules" [16]. At the same time, it is advisable to conduct experimental and numerical studies of both natural and anthropogenic conditions of the coast, as well as to develop and study models of coastal protection structures in the conditions of the studied territory of the coastal urbanized recreational territory $[17,18]$. 
The results of studies of natural processes department of education and environmental characteristics, parameters of Bank-protection structures [19] allowed the authors to specify the principles for the development of the system of environmental-engineering measures to stabilize and/or increase in environmentally safe condition seaside urban recreational areas: - the principle of efficiency: Bank protection structures should provide function at the lowest cost resources;

- the principle of cost-effectiveness: cost savings should be ensured at every stage, from design to commissioning of the facility;

- the principle of sustainability: the design should not negatively impact the ecological status of the protected zone of the coast is to ensure the security of the population or the temporary presence of people from the collapse of the Bank, not to pollute the zone (soil, water) used components or do not create the possibility of pollutants through the structure, as not to affect the flora and fauna in the zone based on the assessment of the degree of impact on the environment $[19,20]$;

- the principle of ensuring the durability structure of construction:

a) in case of aggressive effects of environmental components-sea and atmosphere: the structure must be resistant to repeated alternating freezing-thawing of concrete, the chemical action of sea-water and other aggressive mineralized or fresh-water, atmospheric parameters, wind, wave and a level regime of the coastal zone of the sea);

b) in objectively developing hydrogeological conditions of the shore: the structure should be designed taking into account the parameters of the type of soil, the formed directions and volumes of groundwater flows, the ability to form landslides, etc.;

c) in the conditions of the seismic parameters of the territory;

- the principle of ensuring the maintainability of the structure: the design features of coastal protection structures should be such that, if necessary, to restore the integrity of the structures with minimal financial and material costs.

After selecting the ecological and engineering solution of the coastal protection structure, the predicted indicators of the beach zone environmental safety factors $\left(k_{j k}^{e 2}\right)$ are determined at the fifth stage, followed by the analysis of the overall predicted dynamics of the ESbaF beach zone environmental safety (formula 1).

The change in the level of environmental safety of the beach area $\Delta \mathrm{ES}_{\mathrm{ba}}$ is determined by the formula:

$$
\Delta \mathrm{ES}_{\mathrm{ba}}=\mathrm{ES}_{\mathrm{ba}}{ }^{\mathrm{C}}-\mathrm{ES}_{\mathrm{ba}}^{\mathrm{F}}
$$

Where $\mathrm{ES}_{\mathrm{ba}}{ }^{\mathrm{C}}$ is an indicator of the current dynamics of the ecological safety of the beach zone.

If $\Delta \mathrm{ES}_{\mathrm{ba}} \leq 0$, then the environmental safety of the beach zone is not ensured, this leads to the need of choosing another environmental engineering solution that ensures the environmental safety of the beach zone.

If $\Delta \mathrm{ES}_{\mathrm{ba}}>0$, then ecological safety of the beach zone is ensured by the implementation of the ecological and engineering solution for the construction of coastal protection.

\section{Conclusions}

At the present stage, in coastal recreational zones, the ecological state is characterized by an increase in the number of negative processes under the influence of anthropogenic factors

- the increase in development on the sea coasts increases the level of loads,

- increased wear and tear of shore protection facilities, 
- in some areas, the environmentally safe flow of surface water into the sea is not organized,

- the level of environmental pollution from transport emissions, landfills of solid municipal waste and violations at public utility facilities is increasing.

Because of this, there is an acute conflict between the desire for increasing consumption of coastal resources for recreational purposes and the need to ensure their long-term use with the provision of a comfortable environment, natural landscapes, sufficient width and quality of the beach strip, and the maintenance of an environmentally safe state of coastal territories. This requires monitoring and observing environmental engineering objects state coastal protection needs to account for the collection, accumulation and storage of observational data; creating and maintaining a database of observations; comparison of the measured values of diagnostic indicators of the state of coastal protection structures with their criteria values; informing the authorities interested in the safe state of coastal protection structures at the local level (locally), regional (territorial) and federal levels. Summarizing, the problems of ensuring the environmentally safe state of coastal urbanized recreational areas are relevant and are the main task of their research.

When designing coastal protection structures, it is necessary to provide measures that ensure the environmental safety and reliability of these structures during their construction. At the same time, it is necessary to operate these facilities at a sufficiently high technical level. Only proper and efficient operation of facilities and timely repairs will allow using all incorporated in the draft the perfect ideas, but also to ensure environmental safety and reliability as Bank protection structures and the natural environment.

Testing the potential application of the algorithm of selection of designs Bank protection structures to ensure environmentally safe condition seaside urban recreational areas will further justify the selection of the optimal environmental engineering solutions for the protection of the Western coast of Crimea.

This research was done at the expense of the state program of the Russian Federation "Scientific and technological development of the Russian Federation", the planned period of 2021-2022 years under the Plan of basic research and the Ministry of Construction of Russia RAACS to 2021. Topic 3.2.1.2.

\section{References}

1. G. Sigora, T. Khomenko, L. Nichkova Problems of ensuring an environmentally safe state in the recreational zones of Sevastopol, Economics of construction and nature management, 2 (75), 125-132 (2020)

2. Yu. Goryachkin The current state of the coastal zone of the Crimea, The Ecosystem Hydrophysics, 252 (2015)

3. I. Agarkova-Lyakh Development of exogenous processes on the shores of Sevastopol, Materials of the IV International Scientific and Practical Conference "Applied Aspects of Geology, Geophysics and Geoecology using modern Information Technologies", 28-34 (2017)

4. M. Kukhta, I. Yakovenko Features of functioning and actual tasks of development of the resort and recreational complex of the Republic of Crimea, Industry of tourism and hospitality: state, problems, prospects of development Collection of the AllRussian Student Internet Conference with international participation, dedicated to the 80th anniversary of the DVSUPS and the 15th anniversary of the Department of International Communications, Service and Tourism, 182-186 (2018)

5. N. Vetrova, T. Ivanenko Features of the formation of the ecological state of coastal recreational zones, Construction and technogenic safety, 2, 64-68 (2016) 
6. A. Sanin Coastal morpho-systems of the Crimea and their recreational use, 25.00.25 "Geomorphology and evolutionary geography": dissertation for the degree of Candidate of Geographical Sciences, 140-150 (2014)

7. V. Ivanov, V. Yastreb, Yu. Goryachkin, A. Prusov, V. Zima, V. Fomin Nature management on the Black Sea coast of the Western Crimea: current state and development prospects (Sevastopol: Marine Hydrophysical Institute) 324 (2006)

8. V. Shakhin Transit mass transfer formed by waves on the liquid surface, Economics of construction and environmental management, 3 (76), 148-151 (2020)

9. N. Vetrova, E. Mennanov Approaches to the substantiation of environmentally safe biopositive solutions for the reconstruction of coastal protection structures in the recreational zones of the Crimea, Sustainable development of the territory. Collection of reports of the 2nd International Scientific and practical conference, 53-55 (2019)

10. S. Ivanyuta Complex analysis of the state of natural and technogenic security of the Autonomous Republic of Crimea, Ecological safety and environmental management, 7, 109-127 (2011)

11. V. Trofimov Theory and methodology of ecological geology (Moscow State University Publishing House), 368 (1997)

12. Yu. Goryachkin Coastal erosion and protection in Ukraine, Coastal erosion and protection in Europe, 413-426 (2012)

13. T. Ivanenko Geotechnical features of the coast of the Western Crimea, Construction and technogenic safety, 43, 85-92 (2012)

14. V. Pochtarenko, N. Shvyrlo, A. Lushchik, O. Romanyuk Temporary methodological provisions of ecological and geological mapping (scale 1:50000 - 1:200000): (Simferopol: SONAT Publishing House) 99 (1997)

15. E. Mennanov Evaluation of the recreational attractiveness of the Primorye urbanized territories, Economics of Construction and Nature management, 4(73), 10-15 (2019)

16. SP 277.1325800.2016. A set of rules. Marine coastal protection structures access Mode: http://docs.cntd.ru/document/456055940 (accessed: 15.02.2021)

17. SP 38.13330.2012. Loads and impacts on hydraulic structures (wave, ice, and from ships) access Mode: http://docs.cntd.ru/document/1200095522 (accessed: 15.02.2021)

18. N. Zuev, V. Shakhin, A. Shunko, N. Shunko Experimental studies of wave impact on the coastal protection of the embankment of Yevpatoria, Integration, partnership and innovation in construction science and education,884-888 (2017)

19. E. M. Mennanov, E. E. Mennanov Parameters of the experiment on beach formation in the coastal urbanized recreational territories, Economics of construction and environmental management, 1(74), 17 -23 (2020)

20. N. Vetrova, E. Mannanov The Practice of application: bridges in coastal areas, Construction Economics and natural resources, 3(64), 16 -21 (2016) 